\title{
Prensa y turismo alemán en Canarias
}

\author{
Press and German tourism in Canary Islands
}

\author{
María Teresa Dorn Padilla \\ Universidad de La Laguna \\ teresa.dorn.padilla@gmail.com
}

Recibido: 20 de noviembre de 2012

Aceptado: 20 de diciembre 2012

\section{Resumen}

El sector turístico ha experimentado un notable aumento en España en las últimas décadas y, a su vez, ha incrementado la producción de medios de comunicación encauzados a los turistas y a las comunidades de residentes extranjeros dentro de la estructura mediática española.

Las Islas Canarias, en donde abunda la afluencia de foráneos, representan en la actualidad uno de los focos de difusión más sobresaliente de este tipo de comunicación. Asimismo, los primeros antecedentes conocidos de una iniciativa periodística en lengua extranjera en el país se hallan precisamente en esta zona geográfica, por lo que resulta pertinente prestar una atención individualizada a la singularidad mediática de este archipiélago en cuanto a medios foráneos se refiere.

Teniendo en consideración que las publicaciones periódicas extranjeras más abundantes en el contexto canario son las germanas e inglesas y que sobre estas últimas ya existen varios apuntes y referencias, este artículo se ocupa de la prensa alemana editada en las islas, independientemente de si se continúa o no publicando, dada la inexistencia de estudios previos sobre dicha materia y su relevancia en la memoria cultural de las islas.

Así, la presente investigación recopila y analiza las publicaciones germanas con periodicidad regular del archipiélago, evidencia la repercusión de la afluencia turística alemana en el desarrollo de las actividades periodísticas en esta lengua en las islas y pone de manifiesto la función de periodismo de servicio desempeñada por estos medios en su doble dimensión de vías para promover la cohesión interna de la colonia germana residente en esta zona y facilitar la estancia de los turistas alemanes en el archipiélago. 


\section{Abstract}

The tourism sector has experienced a notable increase in Spain in the last decades and, in turn, has increased the production of media channelled to tourists and foreign residents within the structure communities Spanish media.

The Canary Islands, where it abound the influx of foreigners, currently represent one of the most outstanding of this type of communication dissemination focuses. In addition, the first known history of a journalistic initiative in a foreign language in the country are found precisely in this geographical area, making it relevant individualized attention to the uniqueness of this archipelago in terms of foreign media media refers.

Taking into consideration that the most abundant in the Canary Islands context foreign periodicals are the German and English and that on the latter already exist several notes and references, this article deals with the edited German press on the Islands, regardless of whether you continue or not publishing, given the lack of previous studies on this matter and its relevance in the cultural memory of the Islands.

Thus, this research collects and analyzes Germanic publications at regular intervals of the archipelago, evidence of the impact of the German tourist influx in the development of the journalistic activities in this language on the Islands, and reveals the service journalism role played by these means in its double dimension of ways to promote the internal cohesion of the German colony resident in this area and to facilitate the stay of German tourists in the archipelago.

Palabras Clave: Medios de comunicación extranjeros; publicaciones periódicas alemanas; periodismo de servicio; afluencia turística; residentes germanos; archipiélago canario.

Key Words: Foreign mass media communication; regular German publication; services journalism; foreign influx; German residents; Canary Island

\section{Introducción}

Tanto el turismo como las publicaciones dirigidas a los turistas y residentes extranjeros han aumentado asombrosamente en las últimas décadas en España, en especial en las Islas Canarias.

Esta circunstancia se deja sentir principalmente en la prensa alemana y británica que confluye en este archipiélago, aunque el presente artículo se centra únicamente en las publicaciones germanas que registran una periodicidad regular independientemente de si se continúan o no publicando, puesto que ya existen investigaciones sobre la prensa británica de las islas. 
Entre ellas cabe destacar un estudio sobre los orígenes del periodismo en Tenerife que sitúa al semanario The Tenerife News ${ }^{1}$ como el primer antecedente conocido de un medio de comunicación extranjero ${ }^{2}$ a nivel nacional, algunas investigaciones puntuales sobre ejemplares de prensa como es el caso del periódico The Canary Islands Review ${ }^{3}$, un catálogo sobre la prensa editada en la provincia Grancanaria en el periodo $1840-1972^{4}$ y otra investigación relativa a los periódicos publicados en Lanzarote y Fuerteventura entre 1852 y $1982^{5}$ en donde también se han analizado este tipo de iniciativas.

Sin embargo, en cuanto a la prensa alemana sólo se tiene constancia de un artículo en el que el musicólogo grancanario Lothar Siemens recopila algunos periódicos escritos en alemán en la década de los noventa ${ }^{6}$ de modo que hasta la fecha no se tiene constancia de un análisis detallado sobre el periodismo en esta lengua desde sus inicios en el conjunto del archipiélago.

Por tanto, la razón de ser del presente estudio se debe a la inexistencia de estudios previos acerca de las publicaciones alemanas editadas en Canarias, a pesar de que el turismo es el primordial sustento de la economía de las islas y que la afluencia de alemanes hacia el archipiélago en todas sus formas juega un papel determinante en este contexto, por lo que convendría conocer los puntos de vista desde los que estos medios enfocan la realidad canaria y el papel que desempeñan en el desarrollo de la opinión pública alemana.

El fenómeno periodístico en cuestión podría incluso llegar a ser ventajoso de cara a una nueva alternativa de mercado en el entorno de la comunicación, no únicamente desde el punto de vista del consumo comunicativo de la población foránea, sino desde la perspectiva de la oferta. Además, los alemanes no son el único público al que se dirigen estos medios,

\footnotetext{
${ }^{1}$ YANES MESA, J.A. (2003): Historia del periodismo tinerfeño, 1758-1936. Una visión periférica Tenerife, pp. 268-269 de la historia del periodismo español, Centro de la Cultura Popular Canaria, Santa Cruz de Tenerife.

${ }^{2}$ A lo largo de la presente investigación, el concepto «medios de comunicación extranjeros» hace alusión únicamente a los medios de comunicación foráneos producidos en Canarias, no a la consideración de medios internacionales importados del exterior.

${ }^{3}$ GONZÁLEZ CRUZ, M.I. (1991): «The Canary Islands Review: el periódico inglés de Las Palmas», Parabiblos: Cuadernos de Bibliotecomanía y Documentación, núm. 5/6, Asociación de Amigos de las Bibliotecas Canarias, Las Palmas de Gran Canaria, pp. 39-52.

${ }^{4}$ SAAVEDRA RODRÍGUEZ, J.A. (1972): Catálogo general de publicaciones periódicas en la provincia de Las Palmas, 1840-1972, Tesina inédita, leída el 28 de junio de 1972 en la Facultad de Filosofía y Letras de la Universidad de La Laguna, Tenerife.

${ }^{5}$ FERRER PEÑATE, M. (2012): El periodismo en la periferia de la periferia de Europa Occidental. Prensa, sociedad y opinión pública en Lanzarote y Fuerteventura, 1852-1982, Tesis doctoral inédita, leída el 27 de enero de 2012 en la Facultad de Ciencias de la Información de la Universidad de La Laguna, Tenerife.

${ }^{6}$ SIEMENS HERNÁNDEZ, L. (2002): «Periódicos canarios en alemán: una eclosión de los años 90 », Noticias del Museo Canario, núm. 2, Las Palmas de Gran Canaria
} 
pues los suizos y los austriacos también son consumidores habituales de este tipo de comunicación.

Una vez delimitado el objeto de estudio, conviene aclarar que la hipótesis de este artículo es la existencia de una relación directamente proporcional entre el aumento de los flujos turísticos y migratorios de alemanes hacia las islas y la puesta en marcha de diversas publicaciones en lengua germana en esta zona.

Para intentar verificar dicha hipótesis, se contrastarán las cifras de los turistas y residentes germanos de Canarias con el avance de la comunicación en este idioma en el contexto canario. A su vez, se compendiará la prensa germana editada en el archipiélago destinada tanto a los alemanes de paso como a los residentes en el archipiélago canario y se detectará la función comunicativa ejercida por este tipo de publicaciones para promover la cohesión interna de los alemanes residentes en las islas y facilitar la estancia de los turistas de la misma nacionalidad en dicho lugar.

\section{Metodología}

La base metodológica de la presente investigación radica en el estudio descriptivo y analítico de la prensa alemana editada en el archipiélago, de modo que el método de trabajo aplicado ha consistido en la localización, la identificación y la caracterización de las diferentes nidades de análisis.

Se da la circunstancia de que algunas de las unidades halladas han modificado su cabecera lo largo de su trayectoria periodística. Por esta razón, se ha optado por analizar por separado aquellas publicaciones que, además de haber alterado su encabezamiento, presentan diferentes contenidos y comienzan a reenumerar sus publicaciones desde el principio.

El trabajo de campo ha conllevado rastreos bibliográficos, consultas archivísticas y hemerográficas, la elaboración de una ficha técnica ${ }^{7}$ a modo de instrumento de investigación que incluye los principales datos formales y de contenido de estos medios, entrevistas con los responsables de estas publicaciones y de otros organismos vinculados con los medios germanos.

Adicionalmente, con la intención de asociar el desarrollo de la comunicación en esta lengua con el incremento de los flujos de alemanes hacia las islas, se han recopilado datos

\footnotetext{
${ }^{7}$ La ficha técnica ha sido confeccionada en base a los patrones sugeridos en ALMUIÑA FERNÁNDEZ, C.J. (1977): La Prensa Vallisoletana durante el siglo XIX (1808-1894), Tomo I, Servicio de publicaciones de la diputación provincial de Valladolid, Valladolid, pp. 377-396.
} 
estadísticos sobre los turistas y los residentes germanos a partir de los inicios de este tipo de publicaciones en el archipiélago.

\section{Resultados y discusión}

\subsection{Paralelismo en la evolución de la prensa y el turismo}

En la etapa previa a que el fenómeno turístico cobrara importancia en el archipiélago, es decir, antes de 1960, apenas se tiene constancia de publicaciones germanas que reflejasen cierta periodicidad, y sólo se dan casos aislados de materiales impresos impulsados por organismos promotores del turismo en las islas que incluían textos en dicho idioma, como es el caso de la revista Isla ${ }^{8}$.

El desarrollo de la industria del turismo se comenzó a dejar sentir a raíz del Plan de estabilización aprobado por el Gobierno franquista en 1959, que «introdujo un reajuste general en la economía que, no sin un alto coste social, propició el drenaje al exterior de los excedentes laborales propios y el despegue en el interior del turismo de masas»?

Dicha circunstancia repercutió notablemente en las Islas Canarias debido a la afluencia masiva de población germanohablante, junto con la de otros países centroeuropeos.

Justamente en este periodo aparecieron con mayor ímpetu las iniciativas comunicativas encauzadas hacia los turistas, como la revista Costa Canaria, que en el año 1965 comenzó a plasmar en sus publicaciones los atractivos turísticos insulares a través de contenidos escritos en alemán, español y, en menor medida, inglés.

Adicionalmente, en estos años, concretamente en 1968, se fundó el periódico Teneriffa Woche, el primer impreso dirigido exclusivamente a los turistas y a los residentes de habla germana en las Canarias.

Más tarde, la crisis del petróleo, que se extendió de 1973 a 1981, incidió en la prensa y en el turismo alemán.

Se da la circunstancia de que aún en 1973 se creó un medio de comunicación editado en español, alemán e inglés denominado Dónde y qué -Wo und was - What and where, y que,

\footnotetext{
${ }^{8}$ El Centro de Iniciativas y Turismo de Las Palmas de Gran Canaria fundó la revista Isla en 1945, pero hasta el año 1952 no incluyó textos en alemán.

${ }^{9}$ YANES MESA, J.A. (2009): Las ondas juveniles del franquismo, Ediciones Baile del Sol y Dirección General del Libro, Archivos y Bibliotecas del Gobierno de Canarias, Santa Cruz de Tenerife, p.24.
} 
recién en el año 1981, se registran dos nuevas iniciativas en el archipiélago canario, Wochenspiegel y Kanarisches Magazin.

Por tanto, en el periodo comprendido entre 1973 y 1981 no se pusieron en marcha nuevos medios escritos, aunque tampoco menguaron los pocos existentes, al igual que ocurrió con el sector turístico, pues no disminuyó, pero se estancó considerablemente, en especial entre 1975 y principios de los ochenta.

Conforme avanzan los años ochenta, resurge el incremento de turistas alemanes y se acentúa la urbanización masiva en el sur de las dos islas capitalinas, pero también en los municipios de Tías y Teguise en Fuerteventura, y de Jandía y Corralejo en Lanzarote.

Este periodo de expansión coincide con la aparición en 1983 de Teneriffa Monat en la mentada isla e Insel Rundschau en Lanzarote, y de Fuerteventura Magazin y Fuerteventura Aktuell en 1986 en la isla de Fuerteventura. Tan sólo un año más tarde, se creó Kanar Insel Zeitung en Lanzarote y, en 1989, surgió Teneriffa Journal.

Sin embargo, el apogeo del turismo alemán en las islas se sitúa a principios de los noventa, cuando además se acentúa la demanda de nuevos modelos turísticos, como el rural o el ecológico, y cobra una considerable importancia el turismo residencial, es decir, los llamados residentes de estancia limitada, a los que no se les puede agrupar dentro del colectivo de turistas ni del de residentes ${ }^{10}$

Esta etapa se corresponde con un destacado incremento de estos medios, pues, tan sólo en la década de los noventa, se fundaron más periódicos y revistas de los que se habían venido publicando desde hace tres décadas ${ }^{11}$.Los medios que comenzaron a publicarse en los años noventa son Teneriffa Insel Post, Gran Canaria Insel Post, La Palma Insel Post, La Gomera Insel Post, El Hierro Insel Post, Info Canarias, Der Valle-Bote, Teneriffa Heute, Fuerte, Megawelle Journal, Teneriffa Magazin, Insel Zeitung, Info Sur Tip e Info Sur Tour.

Luego, con la entrada en el nuevo milenio, despega considerablemente el número de turistas y de residentes germanos en las islas, experimentando únicamente una ligera bajada alrededor de 2004.

A su vez, en el año 2000 surgieron Kaktus y Gran Canaria Report, seguidas un año más tarde por seis revistas de la gama Report para cada una de las islas restantes y por Canarias

\footnotetext{
${ }^{10}$ A este respecto se puede consultar HUETE NIEVES, R. \& MANTECÓN, A. (2010): «Los límites entre el turismo y la migración residencial: una tipología», Papers: revista de sociología, no 95, Universidad de Alicante, Alicante, pp. 781-801.

${ }^{11}$ En la década de los noventa se crearon quince empresas periodísticas, mientras que desde 1968 hasta 1990 sólo se registran nueve.
} 
El Paraíso, escrita además de en alemán, en inglés y español. En 2002 aparecieron Canaria Magazin, Hallo Gran Canaria, Kanarische Rundschau y Fuerte Fan Magazin.

Un año después se puso en marcha Teneriffa Nachrichten y en 2004 nacieron Mirador de El Hierro, Teneriffa Panorama, Teneriffas Neue Presse, Der Anzeiger, Teneriffa Canaria Magazin y Qué Pasa Express.

En el año 2005 se crearon Boulevard Canarias, Wochenblatt y Teneriffa geniessen y al cabo de un año se fundaron otros cinco medios; Kanaren Express, Fuerteventura Zeitung, Fuerteventura Magazine Hoy, Lanzarote $37^{\circ}$ y Vitera Plus, y todavía en 2007 surgió la revista Fuerteventura Real.

Por tanto, con la llegada del nuevo milenio no sólo continúan apareciendo un gran número de publicaciones, sino que además lo hacen en cantidades muy superiores a la década de los noventa ${ }^{12}$, tal y como se evidencia en el siguiente gráfico.

\section{NÚMERO DE PUBLICACIONES NUEVAS EN CANARIAS}

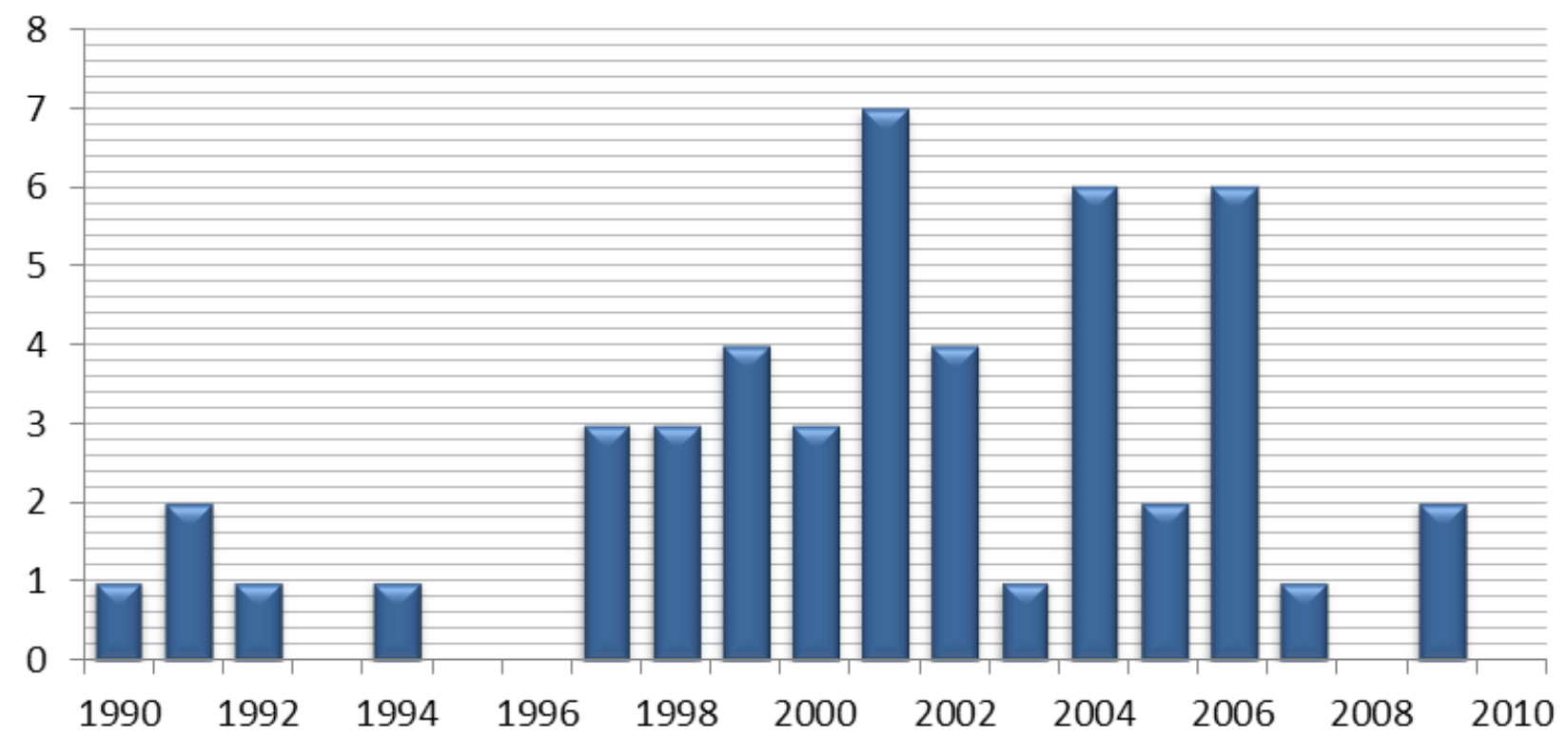

Fuente: Los resultados de la propia investigación.

${ }^{12}$ Concretamente, se fundaron veintidós medios a partir del año 2000. 
No obstante, se aprecia que el advenimiento de la crisis económica ha ido a la par con una desaceleración en la puesta en marcha de nuevos medios de comunicación así como en los registros de empadronamiento y en las cifras de turistas alemanes.

De hecho, desde entonces sólo se han llegado a crear un total de tres nuevos proyectos periodísticos.

El primero, Gran Canaria Olé, en el año 2008, que representa la continuación de la revista Hallo Gran Canaria ${ }^{13}$; el segundo, El Foco, una revista con sede en Fuerteventura y que publica contenidos paralelos en alemán, inglés y español desde 2008; y por último, la revista Canarias en tus manos, creada en el año 2012 y que publica asimismo textos en los tres idiomas anteriormente mencionados.

Pero sumado al hecho de que en los últimos años descendió la puesta en marcha de nuevos medios de comunicación alemanes, se constata que muchos de los existentes dejaron de publicarse, como por ejemplo Teneriffas Neue Presse y Teneriffa Nachrichten en la isla de Tenerife, e Insel Rundschau en Lanzarote.

\subsection{Iniciativas periodísticas por la isla. 1960-2012}

A priori, resulta lógico suponer que en las islas capitalinas se concentra el mayor número de publicaciones alemanas, pero esta conjetura no es del todo cierta.

Tenerife cuenta con la cifra más elevada de medios, concretamente veinte, $y$, abundando en este contexto, Tenerife no sólo sobresale en relación con dicho apunte, sino que también destaca porque registra la cifra más elevada de publicaciones duraderas en comparación con las otras islas, como es el caso de la revista Teneriffa Woche ${ }^{14}$ o del periódico Wochenblatt ${ }^{15}$ cuya tirada es la mayor de las islas.

La excepción se advierte en Gran Canaria, pues sólo se han localizado nueve publicaciones, al igual que en Fuerteventura, a pesar de que una es una isla capitalina y la otra no.

\footnotetext{
${ }^{13}$ La revista Hallo Gran Canaria se fundó en el año 2002.

${ }^{14}$ La revista Teneriffa Woche se publicó ininterrumpidamente durante quince años (1968-1983), hasta que cambió de propietario y pasó a llamarse Teneriffa Monat.

${ }^{15}$ El periódico Wochenblatt es la continuación de Wochenspiegel, fundado en el año 1981 en el Puerto de la Cruz, en la isla tinerfeña.
} 


\section{NÚMERO DE PUBLICACIONES POR ISLAS. 1960-2012}

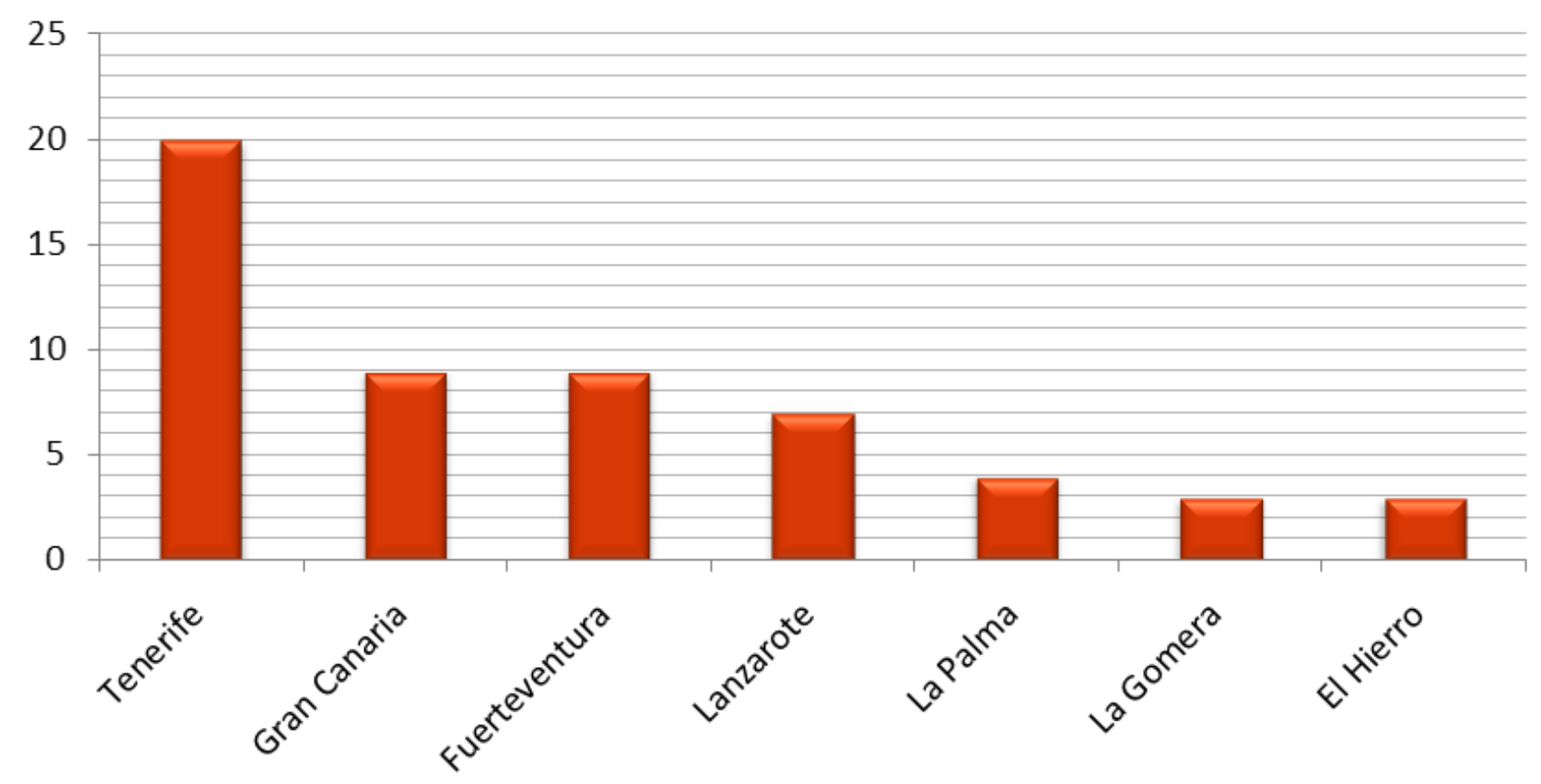

Fuente: Los resultados de la propia investigación.

En el gráfico también se aprecia que la isla de Lanzarote se aproxima considerablemente a Gran Canaria y a Fuerteventura, pues cuenta con un total de siete iniciativas periodísticas.

En las tres islas restantes no se observan tantas apariciones periodísticas, pero sí algunas dignas de reseñar.

De las cuatro iniciativas de La Palma destaca la revista Correo del Valle, fundada en 1994 y cuyo nombre actual es D'Ocasión. Lleva dieciocho años emitiendo ediciones quincenales ininterrumpidamente y sin ningún tipo de suspensión temporal.

En la isla de La Gomera se contabilizan tres medios escritos, entre ellos Der Valle-Bote, una revista que publica contenidos exclusivamente en alemán desde el año 1992.

Entre los tres medios localizados en la isla de El Hierro se halla el folleto informativo Mirador de El Hierro, fundado en diciembre de 2003 y que empezó a publicarse a principios del año 2004. 


\subsection{Características del periodismo alemán en Canarias}

La casi totalidad de los impresos periodísticos localizados a lo largo de esta investigación han sido impulsados por residentes germanoparlantes en las islas ${ }^{16}$.

Hasta bien entrada la década de los sesenta, los alemanes que decidían instaurar un proyecto de comunicación, se veían obligados a hacerse con la colaboración de un español que quisiera convertirse en el propietario del medio, ya que por aquellas fechas un extranjero no podía dedicarse a la edición de periódicos en territorio español.

De esta forma, los primeros medios alemanes localizados en las islas tenían propietarios españoles. Es el caso de Teneriffa Woche, cuyo propietario y director era el periodista tinerfeño Antonio Marti Martín-Fernández, o de Wochenspiegel, que se vio en la obligación de asociarse con el periódico canario Diario de Avisos.

Un número elevado de los medios en cuestión no sobrepasa los cinco años de vida, en algunas ocasiones debido a que el negocio no resultaba rentable $y$, en otras, a que sus responsables directos regresaban a su país de origen y cerraban sus empresas periodísticas.

Aún así, en todas las islas se dan casos de publicaciones duraderas: en Tenerife, Teneriffa Woche, Wochenspiegel (actual Wochenblatt)y Megawelle Journal (actual Megawelle); en Gran Canaria, Info Canarias y Hallo Gran Canaria (actual Gran Canaria Olé); en Fuerteventura, Fuerteventura Magazin y Fuerteventura Aktuell; en Lanzarote, Insel Rundschau; en La Palma, Correo del Valle (actual D'Ocasión); en La Gomera, Der ValleBote; y en El Hierro, Mirador de El Hierro.

A esta singularidad se añade el hecho de que surgieron revistas en las islas capitalinas que han intentado extrapolar su difusión a las islas periféricas, creando publicaciones específicas para cada una de ellas, aunque con poco éxito.

Un ejemplo es la revista Gran Canaria Report, fundada en esa isla en el año 2000. Al año siguiente, comenzaron a publicarse números propios para el resto del conjunto del archipiélago, de manera que durante un tiempo confluían siete ediciones distintas de la revista ${ }^{17}$ que dejaron de publicarse al cabo de algunos años.

\footnotetext{
${ }^{16}$ Cabe apuntar que algunos de sus propietarios y fundadores tenían algún vínculo con el sector inmobiliario.

${ }_{17}$ Gran Canaria Report y Teneriffa Report se publicaban con una frecuencia semestral, pero las cinco revistas restantes presentaban una periodicidad anual.
} 
Entre la prensa alemana en el archipiélago convergen principalmente publicaciones con una periodicidad quincenal y mensual, aunque también se hallan medios de comunicación bimensuales, trimestrales, semestrales y anuales.

En cuanto al precio, se observa que prácticamente la mitad de los medios localizados son distribuidos de forma gratuita y que sus únicos ingresos económicos provienen de las diversas formas de publicidad que insertan entre sus páginas.

El formato más abundante es el de la revista, pues llegan a contabilizarse un total de treinta y siete, seguidas por los periódicos, cuya cifra alcanza la cantidad de dieciséis y, en último lugar, se ha localizado un folleto, Mirador de El Hierro.

La isla en donde se registran más periódicos es Tenerife, en segundo lugar Gran Canaria, y en tercer puesto, Fuerteventura. De hecho, en la presente investigación no se han hallado publicaciones con este formato en las demás islas.

También cabe señalar que uno de los dieciséis periódicos del recuento, Megawelle Journal, se comenzó a publicar en el año 2009 con un formato de revista y modificó su cabecera anterior por Megawelle.

Otros tres periódicos identificados, en concreto Der Anzeiger, Info Sur Tip e Info Sur Tour ${ }^{18}$, contienen exclusivamente anuncios publicitarios, y lo cierto es que presentan un estilo bastante parecido al del conocido periódico español El Baúl.

En cuanto al color de las publicaciones, predominaba el blanco y negro hasta la década de los noventa, etapa en la que las fotografías, los anuncios publicitarios y también algunos titulares a todo color comenzaron a sobreponerse.

También cabe señalar que varios periodistas alemanes han trabajo en distintos medios de comunicación ${ }^{19}$.

\subsection{Análisis de los contenidos}

\footnotetext{
${ }^{18}$ La actual cabecera del periódico Info Sur Tour es Buschtrommel.

${ }^{19}$ Además de los periodistas que han trabajado en diferentes periódicos y revistas, también se observan casos de fundadores, propietarios y directores que han puesto en marcha más de un medio de comunicación en lengua alemana. Uno de los ejemplos más destacados es el periodista Antonio Marti Martín-Fernández, quien era el propietario y a la vez fundador de Teneriffa Woche y de Kanarisches Magazin. Esta circunstancia también se daba entre los comentaristas y colaboradores.
} 
Un ochenta por ciento de las publicaciones periodísticas están escritas íntegramente en alemán, y el restante veinte por ciento, en varios idiomas ${ }^{20}$.

Desde el punto de vista del contenido, se aprecia que escasea la prensa dirigida a todas las islas, pues la mayoría de las iniciativas periodísticas germanas asentadas en Canarias difunden informaciones con carácter eminentemente local.

Algunos periódicos como Wochenblatt o Kanaren Express, se esfuerzan por ofrecer a sus lectores contenidos sobre todo el archipiélago, pero siguen predominando los textos de la isla en donde se ubica su sede.

A pesar de que contadas publicaciones ofrecen informaciones nacionales e internacionales, como por ejemplo las dos anteriormente mencionadas, lo cierto es que la mayoría obvia este tipo de textos, a excepción de algunos acontecimientos ocurridos en su país de origen.

Los contenidos de estos medios abordan asuntos de interés tanto para los turistas como para los residentes de habla germana y procuran satisfacer sus necesidades.

Todos ellos dedican un gran espacio a informar a sus lectores sobre los atractivos turísticos de Canarias, su cultura, su historia y las actividades que pueden realizar en su tiempo libre. En su gran mayoría incluyen temáticas sociales, gastronómicas y relacionadas con la salud y el medio ambiente. En menor medida se tratan temas políticos, económicos y científicos ${ }^{21}$, y, en líneas generales, ningún medio abarca una sección de deporte, pero sí se hace alusión al deporte entendido como actividad de ocio y tiempo libre.

Llama la atención que este tipo de prensa no sólo versa sobre asuntos concernientes al medio ambiente, la naturaleza y el mundo animal, sino que también se preocupa notablemente por cuidar de los mismos.

Sin ir más allá, un periódico generalista como lo es Wochenblatt, refleja en sus páginas varios contenidos relacionados con el abandono de animales, la contaminación y la preservación del medio ambiente canario.

Además, entre los medios analizados también se hallan revistas especializadas en estas materias, como El Foco, en Fuerteventura, que se ocupa de temas relacionados con la naturaleza, el medio ambiente y la flora y fauna; o Vitera Plus, que publica contenidos referentes a la salud.

\footnotetext{
${ }^{20}$ Entre estos idiomas paralelos se hallan el español y el inglés conjuntamente, o sólo uno de los dos.

${ }^{21}$ A excepción de periódicos como Kanaren Express o Wochenblatt.
} 
El género periodístico más empleado por esta prensa es el reportaje, seguido por la noticia y la crónica ${ }^{22}$, presentando un lenguaje cuidado y al alcance de todos los públicos, con manifestaciones lingüísticas típicas de sus países.

\subsection{Un periodismo de servicio}

La prensa en cuestión presenta características propias del periodismo de servicio, es decir, «que no se limita a informar sobre sino para; que se impone la exigencia de ser útil en la vida personal del receptor, psicológica o materialmente, mediata o inmediatamente, cualquiera que sea el grado y el alcance de esa utilidad. La información cuya meta deja de ser ofrecer datos circunscritos al acontecimiento, para ofrecer respuestas y orientación ${ }^{23}$.

Los medios alemanes en Canarias guían a su público, ofreciéndole un amplio abanico de actividades culturales y de ofertas gastronómicas y de ocio, le brinda consejos cotidianos, y le proporciona información de interés, como mapas, números de teléfono y direcciones de utilidad, horarios de apertura de oficinas, comercios, centros médicos, farmacias, y un largo etcétera ${ }^{24}$.

Además, esta prensa no sólo informa a sus lectores, sino que profundiza notablemente en sus contenidos para que éstos cuenten con una información contextualizada para su mejor comprensión, y además pretende que su público haga uso de la información proporcionada, incitándole a la acción, como podría ser acudir a un acto cultural.

Asimismo, estos medios suponen una fuente de información cercana a la que acudir prácticamente en cualquier momento e, incluso, actúan como foro público, pues responden en sus publicaciones a las preguntas formuladas por sus lectores a través de cartas 0 de correos electrónicos, y también les ayudan a solventar sus dudas y problemas.

\section{6. ¿Prensa integradora o segregadora?}

Los medios de comunicación foráneos suscitan un profundo debate en torno a si ayudan a los extranjeros a integrarse en su nuevo espacio territorial, o si, por el contrario, distancian a la comunidad foránea de la población local.

\footnotetext{
${ }^{22}$ También se hace uso de los breves y, en menor medida, de las encuestas.

${ }^{23}$ DIEZHANDINO NIETO, M. P. (1993): «El "periodismo de servicio", la utilidad en el discurso periodístico», Anàlisi, no 15, Barcelona, p. 124.

${ }^{24}$ Algunas publicaciones también contienen la programación televisiva, secciones de moda y belleza y direcciones de iglesias con su correspondiente horario de misas.
} 
Tal controversia es perfectamente extrapolable al contexto canario, en donde se localiza un elevado número de publicaciones extranjeras y se registran sustanciosas altas de empadronamiento de población foránea y de residentes de estancia limitada. Se entiende que dicha polémica no concierne a los turistas vacacionales y visitantes esporádicos, en la medida en que éstos realmente no tienen la necesidad de integrarse en la sociedad canaria, pues acuden a las islas por un corto periodo de tiempo y, transcurrido el mismo, regresan a sus países de origen.

Pues bien, como se apuntó anteriormente, la prensa escrita en alemán tiene la función de periodismo de servicio, y pretende acrecentar el entendimiento de la colectividad germana sobre las Islas Canarias en la mayor parte de sus facetas.

En dicho sentido, se supone que estos medios ayudan a que la comunidad alemana se aclimate en las islas.

Varios académicos, entre ellos Judith Blau ${ }^{25}$, estiman que los medios foráneos pueden llegar a ser una herramienta universal para crear vínculos entre las comunidades extranjeras y las receptoras.

Sin embargo, de otro lado, hay investigadores ${ }^{26}$ que aseguran que la prensa extranjera, al intentar cimentar un sentimiento de comunidad fundamentado en un pasado colectivo, puede obstaculizar la evolución de adaptación cultural de la comunidad foránea con la autóctona.

En esta misma línea, otros estudiosos ${ }^{27}$ de la materia opinan que los medios extranjeros provocan el desarrollo de una doble cultura en un mismo espacio territorial.

A este respecto hay un proyecto de fin de carrera ${ }^{28}$, llevado a cabo en una universidad alemana, que se ocupa precisamente de analizar si la prensa extranjera ayuda a integrar o si, por el contrario, segrega a la comunidad foránea de la local, centrándose en un estudio de casos: los lectores del rotativo alemán Costa del Sol Nachrichten, es decir, «noticias de Costa del Sol», editado en Marbella.

\footnotetext{
${ }^{25}$ BLAU, J.R. (1998): «Immigrant Communities and Their Newspapers in America, 1850-1930», Sociological Analysis, no 1, p. 22.

${ }^{26}$ RIGGINS, S. H. (1992): Ethnic Minority Media: An International Perspective, Sage Publications, Londres.

${ }^{27}$ PORTES, A. y DEWIND, J. (2006): «Un diálogo transatlántico: el progreso de la investigación y la teoría en el estudio de la migración internacional», Universidad Autónoma de México, Zacatecas (México), pp. 7-31.

${ }^{28}$ Böhm, B. (2004): «Auslandpresse zwischen Integration und Abgrenzung. Die Costa del Sol Nachrichten und ihre Leser. Eine empirische Studie.», Proyecto de fin de carrera, presentado en la Facultad de Filosofía de la Universidad de Wilhelm de Westfalia en Münster, Alemania
} 
En este ensayo se pone de manifiesto que la función integradora o segregadora de esta prensa depende directamente de las necesidades y de las motivaciones individuales de los lectores.

Ahora bien, los medios alemanes en Canarias no pueden ser llanamente calificados como agentes socializadores o individualizadores, y tampoco es cuestión de aseverar que ayudan en el proceso de adaptación de la comunidad germana en las islas o que van en contra de la aculturación y de la asimilación de tal grupo poblacional, pues dichas apreciaciones varían según los intereses de quienes consumen estas publicaciones y del conocimiento que tengan del idioma español.

Lo que sí se puede afirmar es que este tipo de prensa constituye un nexo de unión cultural entre ambas comunidades y que traslada a su público el sentimiento de sentirse guiado, protegido y apoyado, consideración esta última en la que también repara el estudio empírico del diario alemán publicado en Marbella.

\subsection{Análisis de los anuncios publicitarios}

A simple vista, todas las publicaciones cuentan con un elevado porcentaje de publicidad, colmado en su mayoría por canarios y por la población alemana en las islas. Este hecho es hasta cierto punto comprensible, pues los anuncios representan su principal y, en numerosos casos, su única fuente de ingresos económicos.

Sin hacer alusión, en este caso, a los periódicos compuestos únicamente por anuncios ${ }^{29}$, en varias ocasiones da incluso la sensación de que contienen más publicidad que texto, como ocurre con la revista Teneriffa Monat.

Además, no toda la publicidad figura en forma de anuncios, sino que también se observa la presencia de publicidad encubierta, en su mayoría en forma de reportajes publicitarios, como es el caso de Teneriffa Woche. Otros impresos, entre ellos Lanzarote 37ㅇ o Wochenblatt, también hacen uso de ciertos reportajes publicitarios, pero los identifican debidamente.

Un alto porcentaje de la publicidad está ligado al sector inmobiliario y, en segundo lugar, a la gastronomía y al ocio, pero también se encuentran anuncios promocionando agencias de viaje, alquiler de vehículos, oficinas, centros médicos, veterinarios, farmacias y servicios de toda índole.

\footnotetext{
${ }^{29}$ Estos periódicos son Der Anzeiger, Info Sur Tip e Info Sur Tour (actual Buschtrommel).
} 
Llama la atención que entre los anuncios particulares se hallan aquellos provenientes de los turistas residenciales que, al regresar a sus países de origen, venden toda clase de objetos usados, desde vehículos hasta electrodomésticos.

Muchos anunciantes de publicidad se repiten en las diferentes publicaciones, sobre todo los relacionados con el sector inmobiliario, el gastronómico y el sanitario, pero también numerosos comercios, locales nocturnos, agencias de seguros como Zürich, empresas de servicio de transporte internacional como Mobiltrans, emisoras de radio alemanas en las islas, etc.

\subsection{Presencia del sector en Internet}

En la actualidad, muchos de estos medios cuentan con una versión digital y, según comentan algunos de sus directores, reciben una alta cifra de visitas diarias.

Adicionalmente, algunos tienen presencia en distintas redes sociales, en su mayoría Facebook y Twitter, donde promocionan sus publicaciones ${ }^{30}$.

Asimismo, en los últimos años han surgido ediciones digitales que nunca antes se habían distribuido en papel, y otras iniciativas periodísticas que suspendieron sus ediciones impresas continúan como medios digitales, lo que pone de manifiesto la fortaleza y la necesidad de este tipo de comunicación en un espacio tan singular como las Islas Canarias.

\section{Conclusiones}

\subsection{Verificación de hipótesis}

Una vez analizados los resultados del presente estudio se constata que los primeros medios de comunicación que incluían textos en alemán entre sus contenidos están íntimamente ligados a la promoción turística de las islas de cara al exterior.

Asimismo, se verifica que las primeras iniciativas periodísticas germanas en el archipiélago están vinculadas a la actividad turística en las islas, y que su evolución va prácticamente a la par con el desarrollo del turismo residencial, fundamentalmente a partir de los noventa, cuando se experimenta una etapa de expansión mediática en todo el archipiélago.

\footnotetext{
${ }^{30}$ Suele darse la situación de que los medios que cuentan con una versión digital también tienen, al menos, un perfil en las redes sociales.
} 
Precisamente en dicha década, la oferta de este tipo de publicaciones estableció un mercado que ha ido aumentando progresivamente hasta que aparecen los primeros indicios de la crisis económica, entre 2007 y 2008 , que inciden de forma negativa en este sector.

A este respecto, también se observa que varias revistas y periódicos alemanes se han visto obligados a cerrar o a dejarse de editar en papel para convertirse en medios digitales, con el único fin de reducir los gastos de impresión ${ }^{31}$.

\subsection{Conclusiones generales}

La mayoría de las publicaciones en cuestión son impulsadas por los propios residentes alemanes ya asentados en las islas, y el resto responde a las posibilidades gananciales y también promocionales, vistas desde la óptica turística.

En líneas generales, la cifra de medios localizados en el archipiélago es elevada, teniendo en cuenta que este fenómeno periodístico es relativamente reciente.

Sin lugar a duda, la isla que cuenta con un mayor número de medios escritos en esta lengua es Tenerife, seguida por Gran Canaria, Fuerteventura y Lanzarote.

En las demás islas de la provincia tinerfeña se registran menos iniciativas periodísticas, pues también se debe tener en cuenta que presentan un menor número de turistas y de población germana empadronada que el resto del archipiélago.

Por su parte, entre los medios rastreados se hallan tanto las publicaciones duraderas como las efímeras, resultando Tenerife la isla que cuenta con más medios longevos y El Hierro la que menos.

El formato que más abunda entre las publicaciones alemanas localizadas es el de la revista, aunque también se registra un destacado número de periódicos.

Además, se concluye que los periódicos escritos en alemán lo son por su impresión en papel y por presentar un formato tabloide, pero no por su frecuencia de publicación, considerando que ninguno dispone de una difusión diaria, pues en su gran mayoría se publican ediciones quincenales y mensuales.

Existen algunas características significativas que diferencian a estas publicaciones de los medios escritos en español, además de las razones lingüísticas obvias.

${ }^{31}$ Dato facilitado por los directores de los periódicos y de las revistas que en la actualidad se publican únicamente como medios digitales. 
En primer lugar, el precio, ya que muchos son gratuitos; en segundo, la distribución, pues se localizan en áreas de tránsito de turistas germanohablantes y donde el número de residentes alemanes es elevado; y por último, sus contenidos.

A través del estudio de los contenidos que vehiculan estos medios de comunicación, se constata que en su casi totalidad tratan asuntos de interés general y que, por lo general, no se especializan en ninguna temática en particular ${ }^{32}$.

En su gran mayoría otorgan una notable preferencia a los temas culturales, gastronómicos, medioambientales y a los relacionados con la salud y con el ocio.

Abarcan principalmente asuntos locales y, en menor medida, temas regionales, aunque algunos hacen referencia a acontecimientos nacionales e internacionales.

La publicidad se encuentra muy ligada a los sectores inmobiliario y gastronómico así como al de la cultura y el ocio, y sus anuncios son reiterativos en diferentes medios.

En términos generales, los lectores de la prensa alemana se componen de turistas en general, turistas residenciales y residentes de habla germana en las islas.

Ahora bien, el perfil de estos consumidores no se corresponde sólo con la idiosincrasia de ciudadanos procedentes de Alemania, sino también de Suiza y Austria, y, en porcentajes muy bajos, de países como Suecia, Bélgica y Holanda.

Dentro de los turistas residenciales y de la población alemana asentada en el archipiélago, predominan los lectores de mediana edad y el colectivo de jubilados que desconoce el español y que dispone de un poder adquisitivo medio o alto.

Según algunos investigadores, la prensa alemana ayuda a este público a integrarse en el colectivo residente y fomenta su cohesión interna, aunque otros académicos apuntan que, por el contrario, puede obstaculizar el desarrollo de adaptación cultural de la comunidad germanoparlante con la autóctona.

De lo que no cabe duda es de la enorme dimensión social que presentan estas publicaciones gracias a su función de periodismo de servicio, pues orientan, aconsejan e incluso intentan ayudar a su público en la medida de lo posible.

\subsection{Dificultades del estudio}

\footnotetext{
${ }^{32}$ Exceptuando a revistas como El Foco, especializada en el medio ambiente, la naturaleza,salud y la flora y fauna.
} 
Lo cierto es que a lo largo del presente estudio han surgido ciertos inconvenientes y contrariedades que han obstaculizado considerablemente esta investigación.

De un lado, la prensa alemana en Canarias presenta una evolución periodística muy irregular en determinados casos, de forma que no se ha podido tener un acceso directo a unos pocos medios indicados a lo largo de este artículo.

A esto se suma el hecho de que en las diferentes bibliotecas y fuentes hemerográficas y documentales consultadas no contaban con la colección completa de los medios alemanes detectados en el presente estudio, por lo que tal carencia se ha solventado mediante consultas a diversas fuentes orales.

Del otro lado, la investigación carece de información en lo concerniente a los gastos y a los ingresos de las distintas publicaciones germanas analizadas, puesto que la mayor parte de los responsables de los medios de comunicación en cuestión oponían cierta resistencia a la hora de desvelar cifras a este respecto.

\subsection{Futuras líneas de inverificación}

En este artículo se vislumbran futuras líneas de investigación, tales como realizar un estudio similar sobre iniciativas comunicativas en otros idiomas puestas en marcha en Canarias y en otros espacios del territorio español, comparar los medios alemanes con otros europeos y muy en especial con Gran Bretaña, pues esta última presenta un número de publicaciones semejante a las alemanas en las islas y en otras regiones nacionales, o analizar si los medios extranjeros influyen en alguna medida en las costumbres arraigadas de la población local.

\section{Bibliografía}

ACIRÓN ROYO, R. (1997): Canarias, prensa y turismo: el turismo como fenómeno de comunicación, Ediciones Idea, Colección Idea Universidad, Santa Cruz de Tenerife

ACIRÓN ROYO, R. (1986): La prensa en Canarias: apuntes para su historia, Caja General de Ahorros de Canarias, Santa Cruz de Tenerife

ALMUIÑA FERNÁNDEZ, C.J. (1977): La Prensa Vallisoletana durante el siglo XIX (18081894), Tomo I, Servicio de publicaciones de la diputación provincial de Valladolid, Valladolid

BEDNAREK, M. (2006): Evaluation in media discourse: analysis of a newspaper corpus, Continuum, Nueva York 
BLAU, J.R. (1998): «Immigrant Communities and Their Newspapers in America, 1850-1930», Sociological Analysis, no 1, pp. 13-24

Böhm, B. (2004): Auslandpresse zwischen Integration und Abgrenzung. Die Costa del Sol Nachrichten und ihre Leser. Eine empirische Studie, Proyecto de fin de carrera, presentado en la Facultad de Filosofía de la Universidad de Westfalia en Münster (WWU), Alemania

DÍAZ NOSTY, B. (2006): Los medios de comunicación en la experiencia migratoria latinoamericana, Fundación Telefónica, Madrid

DIEZHANDINO NIETO, M. P. (1993): «El "periodismo de servicio”, la utilidad en el discurso periodístico», Anàlisi, nำ15, Barcelona, pp.117-125

DIEZHANDINO NIETO, M. P. (1997): «Especialización y periodismo de servicio», en ESTEVE, F. (Coord.): Estudios sobre información periodística especializada, Fundación Universidad San Pablo-CEU, Valencia, pp. 83-91

FERRER PEÑATE, M. (2012): El periodismo en la periferia de la periferia de Europa Occidental. Prensa, sociedad y opinión pública en Lanzarote y Fuerteventura, 1852-1982, Tesis doctoral inédita, leída el 27 de enero de 2012 en la Facultad de Ciencias de la Información de la Universidad de La Laguna, Tenerife

GARCÍA GALINDO, J.A. (2004): «Prensa y turismo en España (Málaga, 18721936): Orígenes y primer desarrollo de una actividad periodística especializada», Centros y periferias: prensa, impresos y territorios en el mundo hispánico contemporáneo: homenaje a Jacqueline Covo-Maurice, Pilar, Universidad de Málaga, Málaga, pp. 169-178

GONZÁLEZ CRUZ, M.I. (1991): «The Canary Islands Review: el periódico inglés de Las Palmas», Parabiblos: Cuadernos de Bibliotecomanía y Documentación, núm. 5/6, Asociación de Amigos de las Bibliotecas Canarias, Las Palmas de Gran Canaria, pp. 39-52

GONZÁLEZ LEMUS, N. (1999): El Puerto de la Cruz y el nacimiento del turismo en Canarias (Apuntes para una interpretación), Edén, Puerto de la Cruz

LÓPEZ ROMERO, L. (2009): «Prensa extranjera en España. La integración social a través de los medios escritos. The Foreign Press in Spain. Social Integration Through Print Media», Telos. Cuadernos de comunicación e innovación, no 80, Fundación Telefónica, Madrid, pp. 116-123

MARTÍN MARTÍN, V.O. (2009): El turismo, motor económico de las Islas, Ediciones Idea, Santa Cruz de Tenerife 
PORTES, A. y DEWIND, J. (2006): «Un diálogo transatlántico: el progreso de la investigación y la teoría en el estudio de la migración internacional», en Repensando las migraciones: Nuevas perspectivas teóricas y empíricas, Colección Migración, México, D.F., pp. 7-31

RAQUEL HUETE, A.M. (2010): «Los límites entre el turismo y la migración residencial. Una tipología», Papers, no 95/3, Universidad de Alicante, Alicante, pp. 781-801

RIGGINS, S. H. (1992): Ethnic Minority Media: An International Perspective, Sage Publications, Londres

SAAVEDRA RODRíGUEZ, J.A. (1972): Catálogo general de publicaciones periódicas en la provincia de Las Palmas, 1840-1972, Tesina inédita, leída el 28 de junio de 1972 en la Facultad de Filosofía y Letras de la Universidad de La Laguna, Tenerife

SIEMENS HERNÁNDEZ, L. (2002): «Periódicos canarios en alemán: una eclosión de los años 90», Noticias del Museo Canario, núm. 2, Las Palmas de Gran Canaria, p.10

VERA, F. (2005): «El auge de la función residencial en destinos turísticos del litoral mediterráneo: entre el crecimiento y la renovación», Papers de Turisme, no 37/38, Universidad de Alicante, Alicante, pp.95-114.

YANES MESA, J.A. (2003): Historia del periodismo tinerfeño, 1758-1936. Una visión periférica de la historia del periodismo español, Centro de la Cultura Popular Canaria, Santa Cruz de Tenerife

YANES MESA, J.A. (2011): «La propaganda radiofónica de la España nacional en Canarias durante la Guerra Civil, 1936-1939», Anàlisi, nº 41, Barcelona, pp. 101-116

YANES MESA, J.A. (2009): Las ondas juveniles del franquismo, Ediciones Baile del Sol y Dirección General del Libro, Archivos y Bibliotecas del Gobierno de Canarias, Santa Cruz de Tenerife

YANES MESA, J.A. (2005): Metodología de la historia de la comunicación social en Canarias: la prensa y las fuentes hemerográficas, Editorial Baile del Sol, Tenerife

\subsection{Fuentes}

Las fuentes primarias a las que se ha recurrido para recabar información sobre este fenómeno comunicativo han sido los propios medios germanos localizados en las islas y, al margen del estudio detallado de estas fuentes primarias, se han consultado las siguientes fuentes complementarias: 


\subsubsection{Fuentes orales}

-Ingo Pangels. Cónsul Honorario de Alemania en Tenerife.

-Peter Schmid. Cónsul de Alemania en Gran Canaria.

- José F. Pérez Bravo. Cónsul Honorario de Alemania en La Palma.

-Roland Mager. Cónsul Honorario de Alemania en Lanzarote y Fuerteventura.

-Anne Lindner. Fundadora de Wochenspiegel (actual Wochenblatt).

-Elmar Wellenkamp. Jefe de redacción de Teneriffa Panorama y periodista con amplia experiencia en medios alemanes de Canarias.

-Regina Danielsen. Jefa de redacción de distintas revistas de Lanzarote.

-Bodo Wilbert. Redactor de varios medios alemanes en Canarias.

-Karen Blanchard. Responsable de medios extranjeros del gabinete de prensa del Cabildo Insular de Tenerife y coordinadora de medios extranjeros de Turismo de Tenerife.

-Noelia Medina. Responsable del mercado alemán del Patronato de Turismo de Gran Canaria.

-Wendy Martín Díaz. Gabinete de prensa de la Viceconsejería de Turismo de Presidencia del Gobierno de Canarias.

\subsubsection{Fuentes hemerográficas}

-Jable: prensa digital de la Universidad de Las Palmas de Gran Canaria

-Biblioteca Pública del Estado en Santa Cruz de Tenerife

-Biblioteca Central de la Universidad de La Laguna

-Biblioteca Virtual de Prensa Histórica del Ministerio de Educación

-Biblioteca digital de prensa canaria de la Universidad de La Laguna

\subsubsection{Fuentes documentales}

- Viceconsejería de Turismo de Presidencia del Gobierno de Canarias

-Agencia Promotur Turismo Canarias del Gobierno de Canarias

-Instituto Nacional de Estadística (INE)

- Instituto Canario de Estadística (ISTAC)

-Aeropuertos Españoles y Navegación Aérea (AENA)

\subsubsection{Fuentes bibliográficas}

-Libro blanco del turismo canario (2a Edición), editado por la entonces Consejería de Turismo y Transporte del Gobierno de Canarias, 1998 
-También se ha consultado una variada bibliografía, entre la que destacan libros, revistas y artículos referentes a la relación entre la prensa y el turismo, a la historia del turismo en las islas, a la prensa turística y a su papel como soporte de integración entre los residentes extranjeros y la población local.

\section{Forma de citar este artículo en bibliografías}

Dorn Padilla, M. T. (2012): "Prensa y turismo alemán en Canarias", en Revista PANGEA, 3, páginas 160 a 182. Red Académica Iberoamericana de Comunicación. Recuperado el _ de de 2 de: http://www.revistapangea.org 